\title{
Artificial Depigmentation of the Skin: Clinical and Pharmacological Aspects in Bangui, Central African Republic
}

\author{
Kobangué $\mathrm{L}^{1 *}$, Gabouga $\mathrm{FL}^{2}$, Grévicko $0^{1}$, Mempanou $\mathrm{T}^{1}$ and \\ Grésénguet $\mathrm{G}^{3}$ \\ ${ }^{1}$ Department of Dermatology and Venerology, National University Hospital Center of \\ Bangui, Central Africa \\ ${ }^{2}$ Department of Dermatology-Venerology, Bangui Community Hospital, Central Africa \\ ${ }^{3}$ Department of Public Health, University of Bangui, Central Africa
}

\section{Research Article \\ Volume 3 Issue 2}

Received Date: March 27, 2018

Published Date: April 12, 2018

DOI: $10.23880 /$ cdoaj-16000146

*Corresponding author: Dr. Léon Kobangué, Department of Dermatology and Venerology of the National University Hospital Center of Bangui, Central Africa, Tel: (236) 75505888; Email: kobangleon@yahoo.fr

\section{Abstract}

Four types of depigmenting products are mainly used: hydroquinone, topical corticosteroids, mercurial derivatives and caustics. Many complications can appear, infectious or not. Our goal was to identify used products and their complications in Central Africa. This was a cross-sectional, analytical, randomized survey of people aged 15 to 75 , lasting four months from March 2016 to June 2016. A prevalence was 46.2\% ( $n=502)$ with a sex ratio of 0.06 . One quarter of the respondents used the products for more than 60 months. Mercurial derivatives (60\%) were the most used. Respondents used product blends in $25.8 \%$ of cases. The common clinical features were: hyperchromia, exogenous ochronosis, poikiloderma and vitilligoid achromia. Vitilligoid achromia, exogenous ochronosis, stretch marks, acne and hyperpilosity were statistically associated with the use of hydroquinone and corticosteroids. Poikiloderma was correlated with the use of mercurial derivatives and hydroquinone. Only exogenous ochronosis, poikiloderma and vitilligoid-achromia were related to duration of use. Exogenous ochronosis, poikiloderma, vitilligoid achromia. The use of mixtures of products was a factor favoring the occurrence of complications. The practice of voluntary depigmentation of the skin is a health problem with several inherent complications. Strong public awareness and product control measures are needed to limit the damage.

Keywords: Voluntary Depigmentation; Pharmacological Aspects, Bangui 
Abbreviations: DV: Voluntary Depigmentation.

\section{Introduction}

Voluntary depigmentation (DV) is a practice whereby a person, on his or her own initiative, works to diminish or eliminate the physiological pigmentation of the skin $[1,2]$. Four types of products are mainly used: hydroquinone, topical corticosteroids (class IV), mercurial derivatives and caustics that are in minority use [3,4]. Many complications may occur, infectious or non-infectious, such as induced or aggravated acne, contact dermatitis, dyschromic dermatosis $[5,6]$. Topical corticosteroids may induce systemic complications, including hypercorticism, hypothalamic-pituitary axis braking with risk of acute adrenalin sufficiency in case of abrupt arrest, induced diabetes, increased arterial hypertension and risk of fetal or infant toxicity in pregnant and lactating women. As for mercurial derivatives, they can induce systemic complications such as glomerular nephropathies, peripheral or central neuropathies, a toxic risk in the fetus with a risk of low birth weight $[7,5]$. Some cases of squamous cell carcinoma have been reported in topical corticosteroid and / or hydroquinone products users [7]. The complications are irreversible with a psychological repercussion (regret and stigmatization). Few data exist on clinical and pharmacological aspects in the Central African Republic. Our research hypothesis was that the complications of DV are very high in the Bangui population and especially related to one of the products used. The goal was to contribute to a better knowledge of the products used and their dermatological complications in the Central African Republic.

\section{Materials and Methods}

This was a cross-sectional, four months study from March 2016 to June 2016. The study population consisted of people aged 15 to 75 , both male and female, residing in Bangui during the study period. The total sample for the city of Bangui was calculated according to the following formula: $\mathrm{N}=\mathrm{pq} \times \mathrm{z}^{2} / \mathrm{i}^{2}$ [8]. We accepted a precision of our estimate in the range of $5 \% . \mathrm{N}=0.71 \times 0.29 \times 1.96^{2} /$ $0.05^{2}=317$ (minimum size). The sample per district was calculated according to the following formula: sample / population of Bangui $\mathrm{x}$ population of each district. Included in this study was anyone between the ages of 15 and 75 who was willing to study. This study excluded anyone refusing to participate in the study. We are limited to 75 years by what we have estimated that beyond this age, the interrogation is more delicate and the skin lesions are more difficult to perceive. The data collection was done by random cluster survey. We interrogated the subjects and had a clinical examination in an isolated place of the different houses, in search of the side effects related to the cosmetic use of depigmenting products. The pharmaceutical classes of the products used were checked on the packaging, if available. The data were collected using a questionnaire that included: identification of the subject (name, age, sex, and residence), sociodemographic profile (occupation, marital status, income, level of education), pharmacological parameters (type of product used, duration of use of the depigmenting products, methods of use of the products), clinical parameters (cutaneous complications related to the use of the depigmenting products). The information's collected were processed using EPI-INFO software (version 7.0). The qualitative variables were compared using the Pearson's Khi-2 test, but for counts less than 5, we used the Ficher test with Yates correction. The Student's test was used to compare the quantitative variables. The differences observed were considered statistically significant for a $\mathrm{p}$ value of less than 0.05 with a $95 \%$ confidence interval $(95 \% \mathrm{CI})$ excluding value 1 . Ethically, the protocol was accepted by the Scientific Committee. acting as Ethics Committee in the country. All participants were informed of the purpose of the project in French or Sango (National Language) and written consent was obtained prior to enrollment. The cards were made anonymous by replacing the names and first names by numbers.

\section{Results}

Two hundred and thirty two (232) users were identified from a total of 502 subjects surveyed, with a prevalence of $46.2 \%$, of which $15(6.47 \%)$ were male and 217 (93.53\%) were female sex; the sex ratio was equal to 0.06 . The distribution of respondents by duration of use showed: 1 to 30 months $(92 / 232=39.7 \%), 31$ to 60 months $(82 / 232=35.30 \%)$ and more 60 months $(58 / 232$ $=25.00 \%$ ). Mercurial derivatives were the most commonly used active substances (60\%), followed by corticosteroids (21\%) and hydroquinone (19\%). The distribution of the respondents according to the use of the depigmenting products showed that $74.2 \%$ used a single pharmacological class against the 25.8 who used the mixtures. Table 1 shows the frequency of the clinical aspects of the skin observed in the users of the depigmenting products. Pigmentary disorders such as exogenous ochronosis were the most common manifestations (Figure 1). 


\begin{tabular}{|c|c|c|}
\hline Clinical aspects of the skin & Number of users (n=232) & Percentage \\
\hline Hyperchromic joints & 214 & 92,2 \\
\hline Periorbital hyperchromia in glasses & 204 & 87,9 \\
\hline Exogenous ochronosis & 143 & 61,6 \\
\hline Poikiloderma & 116 & 50,0 \\
\hline Vitiligoid achromia & 92 & 39,7 \\
\hline Pruritus & 79 & 34,1 \\
\hline Stretch marks & 55 & 23,7 \\
\hline Acne & 50 & 21,6 \\
\hline Hyperpilosity & 48 & 20,7 \\
\hline
\end{tabular}

Table 1: Frequencies of the clinical aspects of the skin.

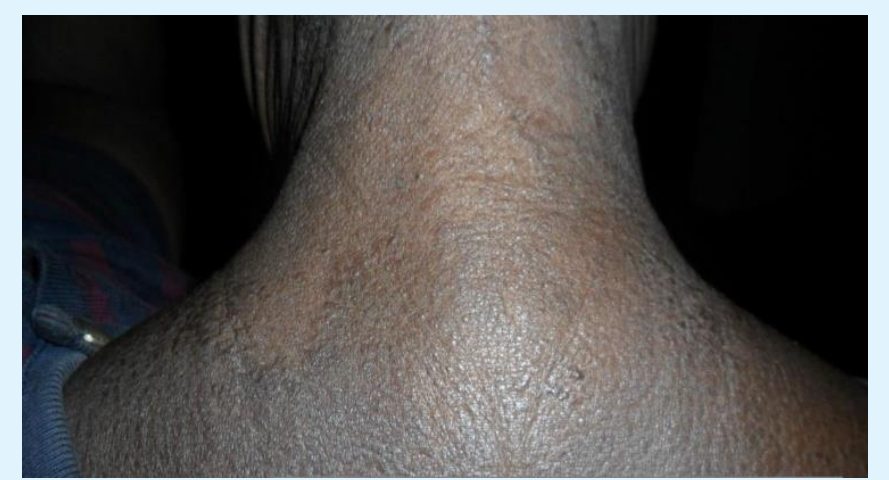

Figure 1: Exogenousochronosis.
The complications found were: cutaneous atrophy (8.2\%), pityriasis versicolore (7.8\%), diffuse dermatophytia (5.6\%), scallops (5.6\%), eczema and contact dermatitis $(8.1 \%)$, ecthyma $(3.0 \%)$, erysipelas (2.6\%), poikiloderma $(2.6 \%)$, lupus like lesions $(1.3 \%)$, bluish appearance of ear conch (1.3\%), pseudo-folliculitis $(0.9 \%)$ and impetigo (0.4\%). Table 2 shows the distribution of the clinical aspects of the skin according to the pharmaceutical classes of the depigmenting products.

\begin{tabular}{|c|c|c|c|c|c|c|c|}
\hline \multirow{3}{*}{ Clinical aspects } & \multicolumn{6}{|c|}{ Pharmaceutical classes } & \multirow{3}{*}{ P Value } \\
\hline & \multicolumn{2}{|c|}{ Corticosteroids } & \multicolumn{2}{|c|}{ Mercurial derivatives } & \multicolumn{2}{|c|}{ Hydroquinon } & \\
\hline & $(n=62)$ & $\%$ & $(n=176)$ & $\%$ & $(n=56)$ & $\%$ & \\
\hline Hyperchronic joints & 55 & 88,71 & 163 & 92,61 & 51 & 91,07 & 0,795 \\
\hline Periorbital hyperchromia & 53 & 85,48 & 154 & 87,50 & 50 & 89,29 & 0,823 \\
\hline Exogenousochronosis & 46 & 74,19 & 100 & 56,82 & 43 & 76,79 & 0,005 \\
\hline Poikilodermia & 14 & 22,58 & 106 & 60,23 & 10 & 17,86 & $<0,0001$ \\
\hline Vitiligoid achromia & 36 & 58,06 & 57 & 32,39 & 35 & 62,5 & $<0,0001$ \\
\hline Pruritus & 26 & 41,94 & 55 & 31,25 & 24 & 42,86 & 0,1148 \\
\hline Stretch marks & 43 & 69,35 & 15 & 8,52 & 40 & 71,43 & $<0,0001$ \\
\hline Acne & 41 & 66,13 & 11 & 6,25 & 39 & 69,64 & $<0,0001$ \\
\hline Hyperpilosity & 27 & 43,55 & 21 & 11,93 & 27 & 48,21 & $<0,0001$ \\
\hline
\end{tabular}

Table 2: Distribution of the clinical aspects of the skin according to the pharmaceutical classes of the depigmenting substances used.

Table 3 shows the distribution of clinical aspects cosmetics. according to the duration of use of depigmenting 


\begin{tabular}{|c|c|c|c|c|c|c|c|}
\hline \multirow{3}{*}{ Clinical aspects } & \multicolumn{6}{|c|}{ Duration of use } & \multirow{3}{*}{$P$ value } \\
\hline & \multicolumn{2}{|c|}{ 1-30 months } & \multicolumn{2}{|c|}{ 31-60 months } & \multicolumn{2}{|c|}{$>60$ months } & \\
\hline & $(n=92)$ & $\%$ & $(n=82$ & $\%$ & $(n=58)$ & $\%$ & \\
\hline Hyperchromic joints & 83 & 90,0 & 76 & 87,8 & 55 & 94,8 & 0,579 \\
\hline Periorbital hyperchromia in glasses & 76 & 82,6 & 75 & 91,4 & 53 & 91,3 & 0,130 \\
\hline Exogenousochronosis & 42 & 45,6 & 53 & 64,6 & 48 & 82,7 & $<0,0001$ \\
\hline Poikilodermia & 42 & 45,6 & 36 & 43,9 & 38 & 65,5 & $<0,0001$ \\
\hline Vitiligoid achromia & 30 & 32,6 & 31 & 37,8 & 31 & 53,4 & 0,036 \\
\hline Pruritus & 31 & 33,6 & 32 & 39,0 & 16 & 27,5 & 0,370 \\
\hline Stretch marks & 21 & 22,8 & 23 & 28,0 & 11 & 18,9 & 0,446 \\
\hline Acne & 19 & 20,6 & 18 & 22 & 13 & 22,4 & 0,962 \\
\hline Hyperpilosiy & 16 & 17,4 & 21 & 25,6 & 11 & 19 & 0,382 \\
\hline
\end{tabular}

Table 3: Distribution of the clinical aspects of the skin according to the duration of use of the cosmetic products.

Only exogenous ochronosis $(\mathrm{p}<00.1)$, poikiloderma and vitilligoid achromia $(p<0.05)$ were related to duration of use. They were more common after 60 months of use. The distribution of the clinical aspects of the skin according to the modes of use of the depigmenting products is shown in the Table 4.

\begin{tabular}{|c|c|c|c|c|c|}
\hline \multirow{2}{*}{ Clinical aspects } & \multicolumn{4}{|c|}{ Modes of use } & \multirow{2}{*}{ P value } \\
\cline { 2 - 5 } & Products Mixture & \multicolumn{2}{|c|}{ One depigmenting product } & \\
\cline { 2 - 5 } & $\mathbf{( n = 6 0 )}$ & $\mathbf{\%}$ & $\mathbf{( n = 1 7 2 )}$ & $\mathbf{\%}$ & \\
\hline Hyperchromicjoints & 55 & 91,6 & 159 & 87,4 & 0,348 \\
\hline PeriorbitalHyperchromia & 53 & 88,3 & 151 & 56,3 & 0,026 \\
\hline Exogenousochronosis & 46 & 76,6 & 97 & 59,3 & $<0,001$ \\
\hline Poikilodermia & 14 & 23,3 & 102 & 32,5 & $<0,001$ \\
\hline Vitiligoideachromia & 36 & 60 & 56 & 30,8 & 0,169 \\
\hline Pruritus & 26 & 43,3 & 53 & 65,1 & $<0,001$ \\
\hline Stretch marks & 43 & 71,6 & 112 & 5,2 & $<0,001$ \\
\hline Acne & 41 & 68,3 & 9 & 12,2 & $<0,001$ \\
\hline Hyperpilosity & 27 & 45 & 21 & & \\
\hline
\end{tabular}

Table 4: Distribution of the clinical aspects of the skin according to the modes of use of the depigmenting products

Exogenous ochronosis, poikiloderma, vitilligoid achromia, pruritus, stretch marks, acne and hyperpilosity were related to the mode of use. The use of product mixtures was a factor favoring the occurrence of complications.

\section{Discussion}

The difficulty encountered in carrying out this study was the reluctance of some practitioners of voluntary depigmentation who did not want to talk about the subject. In addition, the cost of the additional tests required to confirm systemic effects limited our work to only clinically detectable complications. In our series, $3 / 4$ users used cosmetic depigmenting for less than 60 months and $1 / 4$ exceeded 60 months. Our data on the duration of use of the products, are super imposable with those found in Bamako by Saye who reported in his work that $64 \%$ of the users practiced DV for less than 50 months with an average duration of use of 37 months [9]. Mercurial derivatives were by far the most used with a frequency of $60 \%$. These results are similar to those of Pitché, et al. in Lomé who reported a predominance of use of mercurial derivatives (30.9\%) compared with hydroquinone (24\%) and corticosteroids (18.9\%) [4]. In contrast, in Dakar, Mahé noted a predominance of hydroquinone use (89\%), followed by corticosteroids $(70 \%)$ and mercurial derivatives (10\%) [10]. Saye in Bamako found equal use of corticosteroids and hydroquinone (51\%) [9]. According to him, mercurial derivatives were the least used (7\%). In Brazzaville, Gathse noted that the most used products were based on 
hydroquinone (38.4\%) and topical corticosteroids (30.7\%) [11]. Kebe, mean while, noted a large use of corticosteroids in $52 \%$ of cases in Nouakchott [12]. The most used pharmaceutical class would therefore vary depending on the localities and may be related to the availability of products? In our study, nearly $3 / 4$ of users would use a single product compared to $25.8 \%$ who used blends. These data were different from those found in Bamako by Saye who found a predominance of use of product mixtures (61.80\%) [9]. This could be explained by the accessibility of the products and also by the habits (mores) of the users. Thus, a socio-anthropological study would be necessary to explain the motivations, the sociodemographic characteristics and the cultural habits of use of the cosmetics of the different populations. In clinical terms, pigment disorders were the top six skin lesions associated with the use of depigmenting agents. These data corroborate those of many authors [2-4,13]. Gathse, et al. in Brazzaville found, in a sample of 104 people, $27.8 \%$ of cases of pigmentary disorders in front of $27.7 \%$ cases of infectious disorders, $24 \%$ of cases of acne, $15,1 \%$ cases of allergic disorders, $9.5 \%$ cases of dystrophic disorders, $4.8 \%$ of cases of papullosa dermatoses [11]. For their part, Mahé, et al. noted in their work a predominance of stretch marks (40\%), followed by $29 \%$ of acne, $10 \%$ of hyperpilosity, $6 \%$ of exogenous ochronosis, $6 \%$ of poikiloderma, and $3 \%$ pruritus [14]. The differences observed in the data would be related to methodological approaches. The distribution of the clinical aspects of the skin according to the pharmaceutical class of the substances used made it possible to note that certain complications were related to the products used. In fact, vitilligoid achromia (p $<0.0001$ ), exogenous ochronosis ( $p<0.0001$ ), stretch marks ( $\mathrm{p}<0.0001)$, acne ( $\mathrm{p}<0.0001)$, and hyperpilosity was related to the use of hydroquinone. Poikiloderma was correlated with the use of mercurial derivatives ( $p$ $<0.0001$ ). These data are substantially similar to those found by Petit who noted that dyschromic disorders, irritation dermatitis, were correlated with the use of hydroquinone [2]. But, he also reported that hyperpilosity, acne and stretch marks were related to the use of corticosteroids; which is different from the data in our series.

Del Giudice, et al. have reported that dyschromicdermatosis is secondary to prolonged use of hydroquinone [3]. Moreover, they revealed cases of acne induced or aggravated, often obviously very corticodependent. The distribution of the clinical appearance of the skin according to the duration of use of the depigmenting products made it possible to observe that only exogenous ochronosis ( $p<0.01$ ), poikiloderma and vitilligooidachromia ( $p<0,05)$ were related to the duration of use. They were more common after 60 months of use. We did not find any comparative elements in the literature. The distribution of the clinical appearance of the skin with respect to the mode of use showed us that exogenous ochronosis $(p=0.026)$, poikiloderma $(p<0.001)$, vitilligooidachromia $(p<0.001)$, Stretch marks (p <0.001), acne (p <0.001) and hyperpilosity $(\mathrm{p}<0.001)$ were related to the mode of use. Indeed, the use of mixtures of products was a factor favoring the occurrence of complications. On this point too, we did not find any data from the literature.

\section{Conclusion}

Nearly half of the subjects surveyed in the city of Bangui practiced voluntary depigmentation with a clear predominance of women and young subjects. All the pharmacological classes of depigmenting cosmetics are used with a predominance of mercurial derivatives, very toxic products. The main cutaneous complications detected were dyschromic dermatoses. The occurrence of certain complications was correlated with the pharmaceutical class of the products used, the duration of use and the mode of use. Our work has thus made it possible to note that the voluntary depigmentation of the skin remains a problem of great scale on the medical plan, hence the need for public awareness and effective reprehensible measures by the public authorities. In addition, studies with biological examinations will make it possible to better appreciate the systemic effects of this practice.

\section{References}

1. Petit A (2007) La dimension addictive de la dépigmentation volontaire. Clinique transculturelle pp : 77.

2. Petit A (2006) La dépigmentation volontaire : réalités, interprétations, résistances. Clinique transculturelles, pp: 119.

3. Del Giudice P, Raynaud E, Mahe A (2003) L'utilisation cosmétique de produits dépigmentants en Afrique. Bull Soc Pathol Exot 96(5): 389-393.

4. Pitche $\mathrm{P}$, Afanou A, Amanga Y, Tchangai Walla K (1998) Les pratiques cosmétiques dépigmentantes des femmes à Lomé (Togo). Méd Afr Noire 45(12): 709-713. 
5. Morand JJ, Fly F, Lightburn E, Mahe A (2007) Complications de la dépigmentation cosmétique en Afrique. Med Trop 67: 627-634.

6. Yoboue P, Sangare A, Kaloga M, Kouadio A, Djedje MA (2005) Epidemiologic and etiologic features of pigmentation disorders observed during consultation at the dermatology center of Abidjan, Ivory Coast. International journal of dermatology 44(1): 33-34.

7. Agence Francaise de Securite Sanitaire des Produits de Sante (2011) Evaluation des risques liés à la dépigmentation volontaire.

8. Nagobe M (1999) Causes et conséquences de la dépigmentation artificielle des femmes à Bangui. Mémoire de CAPES, Bangui, pp: 37.

9. Saye G (2007-2008) Complications oculaires observées chez les utilisatrices des produits cosmétiques au centre de santé de la commune du district de Bamako. Thèse de doct médecine, Univ de Bamako, pp: 64.
10. Mahe A (2010) Dermatologie tropicale, DESC de pathologies infectieuses et tropicales. Meaux, pp: 51.

11. Gathse A, Obengui, Ibara JR (2005) Motifs de consultations liés l'usage des dépigmentants chez 104 utilisatrices à Brazzaville, Congo. Santé public 98(5): 387-389.

12. Kebe M (2011) La dépigmentation artificielle et ses complications chez les consultantes au service de dermatologie du centre hospitalier national de Nouakchott; mémoire de master de santé publique, univ de Nouakchott, pp: 1-34.

13. Raynaud E (2001) Dépigmentation cutanée à visée cosmétique: Prévalence, profil sociologique et motivation. Enquête réalisée dans une population féminine hospitalisée à Dakar (Sénégal). Thèse de doct Médecine, Univ Paris V Réné Descartes.

14. Mahe A, Ly F, Aymard G, Dangou Jm (2003) Skin diseases associated with the cosmetic use of bleaching products in women from Dakar, Sénégal. Br J dermatol 148(3): 493-500. 